\title{
Visualidades e subjetividades juvenis: sobre a criação poética no ensino de artes visuais na escola
}

\section{Leandro de Souza Silva}

Professor do Departamento de Artes Visuais (DAV), Colégio Pedro II.

Rio de Janeiro.

Mestre em Artes pela UERJ.

ORCID: https://orcid.org/0000-0002-6140-9681

E-mail: leandrosouza@cp2.g12.br 


\section{Resumo}

O presente trabalho parte de reflexões acerca dos acontecimentos estéticos, poéticos e subjetivos das visualidades advindas do processo de criação de estudantes do Ensino Médio, no Colégio Pedro II, Campus Realengo II, na Zona Oeste do município do Rio de Janeiro. Buscou-se compreender em que medida tais criações visuais adquirem atributos de abrangência artística e poética, além disso, como podem contribuir para novas abordagens pedagógicas. Para o desenvolvimento da análise, este trabalho dialoga com as subjetividades juvenis e, para tanto, foram utilizadas a revisão de literaturas recorrentes ao campo do Ensino de Artes Visuais e estudos em Cultura Visual, numa abordagem qualitativa de interpretação polissêmica da produção artística dos/as estudantes. Consequentemente, soma-se aos estudos sobre processos de ensino/aprendizagem e experiências que transbordam o conteúdo formal e os limites institucionais.

Palavras-chave: artes visuais; cultura visual; ensino; subjetividades.

\section{Abstract}

The present work starts from reflections about the aesthetic, poetic and subjective events of the visualities arising from the creation process of high school students, at Colégio Pedro II, Campus Realengo II, in the West Zone of county of Rio de Janeiro. We sought to understand the extent to which such visual creations acquire attributes of artistic and poetic scope, in addition, how they can contribute to new pedagogical approaches. This work dialogues with the subjectivated youths and for the development of the analysis, the review of recurrent literatures in the field of Visual Arts Teaching and studies in Visual Culture was used, in a qualitative approach of polysemic interpretation of the artistic production of the students. Consequently, it is added to studies on teaching / learning processes and experiences that overflow the formal content and institutional limits.

Keywords: visual arts; visual culture; teaching; subjectivities. 


\section{Introdução}

A diversidade de trocas experimentadas no contexto da sala de aula e em todo o espaço de convivência escolar pode oferecer novas descobertas para quem se envolve nos processos pedagógicos. Diante disso, questionamos se o que se vive na escola pode, de alguma forma, transbordar o caráter acadêmico, disciplinar e, por conseguinte, pedagógico. Em virtude das relações que ali são, antes de tudo, relações humanas, este texto nos convida a pensar sobre o que emerge das experiências artísticas provenientes do Campus Realengo II do Colégio Pedro II.

Nesse sentido, o presente artigo articula-se nas dinâmicas do "afetar e ser afetado", "o deixar-se afetar", inspiradas pelas contribuições de Deleuze (2002) e pelo respeito às autonomias individuais no ensino/aprendizagem propostos por Paulo Freire (1996) acerca das vivências escolares. Desse modo, a ideia originária é analisar as questões subjetivas que entram em jogo na criação visual realizada nessa escola. Num primeiro momento do trabalho, serão apresentadas fotografias que registram a performance artística desenvolvida por estudantes do 10 ano do Ensino Médio, no decorrer de aulas de Artes Visuais do Colégio Pedro II (CPII), no Campus Realengo II, localizado na Zona Oeste do município Rio de Janeiro, no ano de 2014.

Por meio e a partir desses registros, este trabalho também busca pensar quais possíveis contribuições tais imagens oferecem à formação acadêmica e visual dos/as estudantes. Por conseguinte, a relevância de sua participação no Ensino de Artes Visuais, em confluência com a Educação em Cultura Visual, no contexto da Educação Básica.

Essa análise parte dos interesses pelas imagens criadas pelas juventudes na escola, relacionando como circulam e se articulam nos cotidianos tanto de 
professores quanto de estudantes. Além disso, valendo-se das possibilidades oferecidas pela mediação de ações artísticas em sala de aula, pensamos sobre as relações e interações com procedimentos de criação imagética de viés pedagógico, mas sem abrir mão da poética que, em minha análise, vem contribuindo com a compreensão e percepção de mundo e de suas próprias subjetividades.

Assim, o uso das fotografias neste trabalho terá seu devido espaço e será, portanto, tão importante quanto a produção textual na forma de articular o pensamento e o desenvolvimento teórico-metodológico de investigação numa abordagem qualitativa. Tais elementos servem como fonte de informações ou mesmo para a realização de ações investigativas, pois são compreendidas como objetos das subjetividades e das análises que se pretendemos realizar. Para tal análise, também utilizaremos relatos de estudantes, instrumentos normativos no que se refere ao Projeto Político Pedagógico Institucional (PPPI) e leitura de imagens de artistas contemporâneos.

Para compreensão desse fenômeno, tomamos por base teórico-conceitual as contribuições de diferentes autores. No campo da Arte/Educação contemporânea, lançamos mão dos estudos organizados por Ana Mae Barbosa (2010), no campo de Estudos em Cultura Visual, utilizamos os conceitos propostos por Raimundo Martins e Irene Tourinho (2011), Belidson Dias (2011) e Nicholas Mirzoeff (2016), já para a abordagem filosófica, as ideias de Gilles Deleuze (2002) e Jacques Rancière (2012), cuja contribuição fornece também ao trabalho o escopo desta reflexão.

Somado a isso, ainda no campo analítico, o processo de criação visual produzido pelas juventudes encontradas na escola em questão, carregam subjetividades e serviram de objeto de pesquisa em diálogo com as reflexões e definições dos autores mencionados. Nessa perspectiva, tais leituras e análises, permeadas por novos olhares e desdobramentos de práticas pedagógicas, 
estimulam a criação de condições a favor da formação humana efetivamente emancipadora.

\section{Fundamentação Teórica}

Sobre poéticas, visualidades e escola

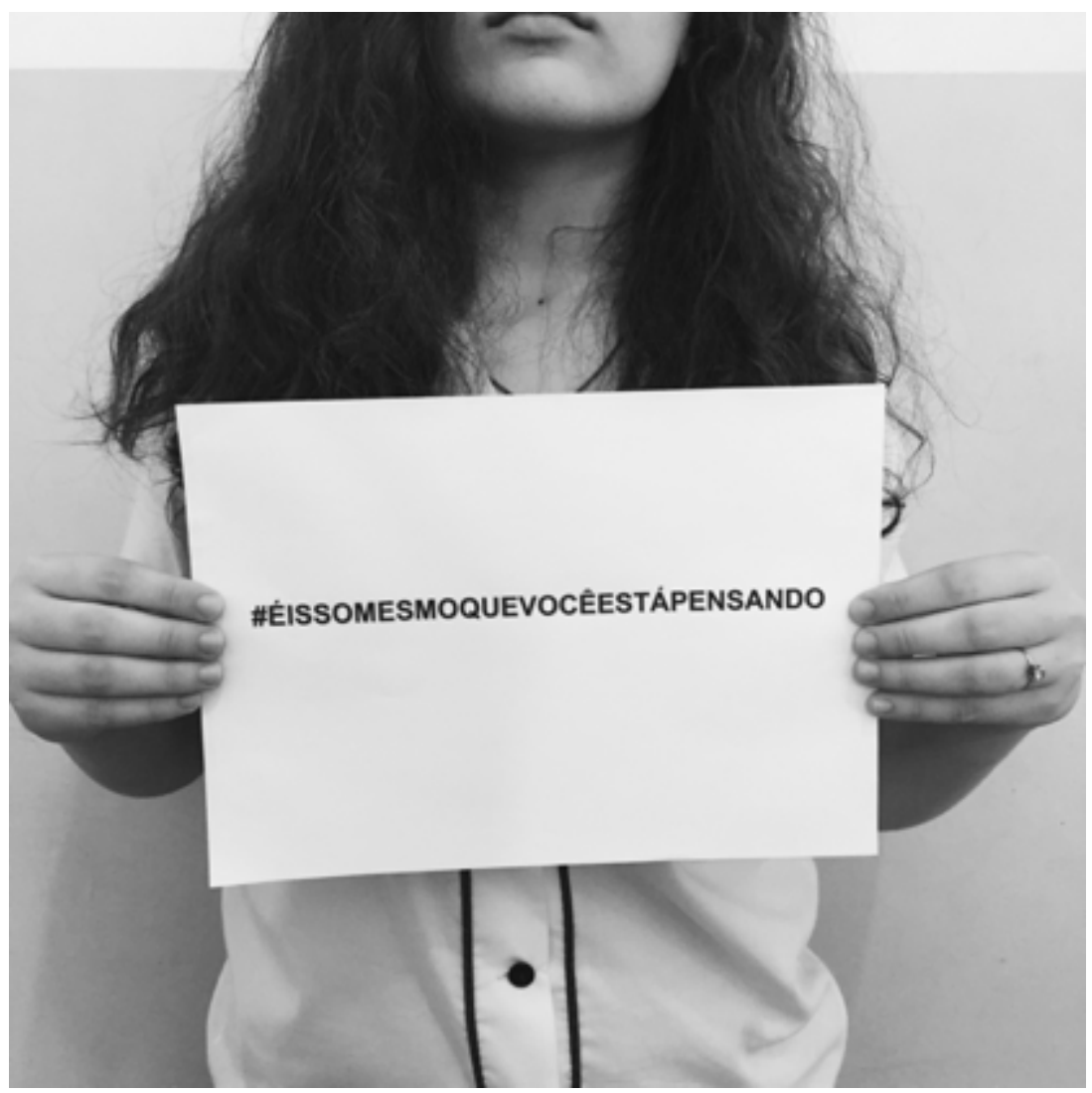

Imagem 1 - \#prontofalei, acervo do autor, 2014.

Uma das formas de iniciar este texto é fazer uma breve recuperação das sensações experenciadas por nós - estudantes e professor - durante a proposta artísticopedagógica, que foram mobilizadas a partir das questões que pretendemos analisar.

Imóveis, e de pé, estudantes foram distribuídos por diversos espaços do campus no horário do intervalo, colocavam-se diante de colegas e professores segurando em suas mãos uma folha com frases no mínimo curiosas, 
provocativas. O incômodo que causavam com seus corpos paralisados e expressões difíceis de qualificar, soavam como confronto, desafio, mas sobretudo deixava em dúvida quem os observava.

A esta altura, era inevitável não lembrar-se de Deleuze quando anuncia que "um corpo afeta outros corpos, ou é afetado por outros corpos: é este poder de afetar e de ser afetado que define um corpo na sua individualidade" (DELEUZE, 2002, p.128). Assim, insurgia em quem os olhava um incômodo que entrecruzava palavra, significados, presença de corpos, olhares e provocações.

Nos corredores se ouvia "isto é coisa de arte", o que instigava ainda mais os/as protagonistas da ação a manterem suas expressões faciais intactas, enquanto aguardavam a frase ser lida. Quando trocavam de posição e se deslocavam para outros espaços do colégio, os demais estudantes interrompiam sua pausa entre as brincadeiras e a refeição para correr a tempo de entender o que é que estava de fato acontecendo durante aqueles infinitos trinta minutos de recreio. Afinal, considerar a autonomia desses movimentos, impressões e sensações é o que Freire (1996) nos convoca a respeitar, afinal é um imperativo ético - e não um favor - do nosso papel profissional como professores/as.

O palco deste acontecimento é o Campus Realengo, cuja constituição nessa área do município do Rio de Janeiro, por si só revela o diferencial que exerce sobre o contexto educacional da região, o que contribui para a contextualização sociocultural deste trabalho. 


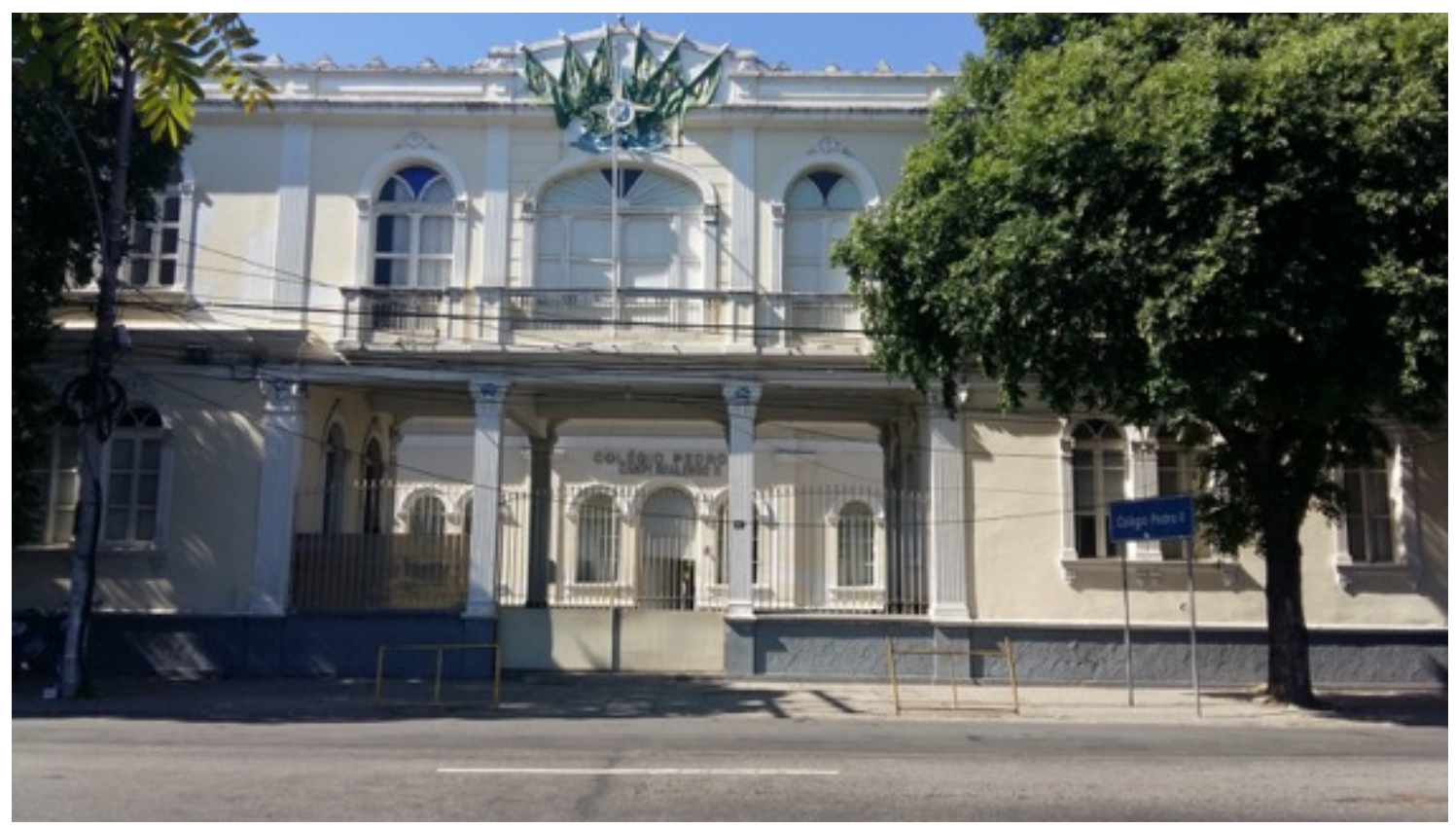

Imagem 6 - Fachada do Campus Realengo (Rua Bernardo de Vasconcelos)

Estabelecido numa área de aproximadamente $50 \mathrm{mil} \mathrm{m²}$, o que hoje são as dependências do CPII, outrora abrigava a Fábrica de Cartuchos do Realengo, com arquitetura que reflete os moldes estéticos do final do século XIX. Sua construção eclética pertencia ao Ministério da Guerra, sediado no bairro entre os anos de 1898 e 1977 (VIANA, 2016).

O campus possui uma estrutura física singular que abriga, além dos espaços escolares habituais, uma grande área verde e conta com um grande complexo poliesportivo, o Centro de Inclusão Digital Professor Wilson Choeri, o Teatro Bernardo Pereira de Vasconcelos e também, a Escola de Música, onde funciona o Ensino Médio Técnico Integrado em Instrumento Musical. Atende 1.877 estudantes, de acordo com dados do Censo Escolar/INEP (2014), da Região da Zona Oeste e municípios vizinhos - nos últimos anos do Ensino Fundamental, Ensino Médio Regular e Técnico e PROEJA - e modifica a realidade de estudantes e suas famílias com a oportunidade de acesso à educação de qualidade e pública. 
O campus oferece dois ateliês para as aulas de Artes Visuais, área específica de conhecimento legitimada oficialmente no currículo da escola, lecionada por profissionais com formação específica, organizados por estrutura departamental composta de aproximadamente 60 docentes, distribuídos nos demais campi do Colégio. A disciplina está presente desde a Educação Infantil até o 10 ano do Ensino Médio e se organiza em equipes por campus com coordenação pedagógica com formação específica em Artes Visuais, e desse modo, articula-se entre cada etapa de formação escolar.

Além das salas de artes/ateliês, o campus também possui no foyer da Escola de Música, uma galeria de exposições, que se soma à estrutura da instituição de ensino federal e, ao se estabelecer no subúrbio do município do Rio de Janeiro, inegavelmente contribui para oportunidades ímpares de acesso à Educação, haja vista tamanha estrutura, não apenas física, mas também de formação do corpo de profissionais que atuam no colégio. Na ocasião, eu aprofundava os estudos no mestrado em Artes e percebia que atuar como professor numa realidade como esta, inaugurava vivências pedagógicas que poderiam contribuir para minha pesquisa científica e acadêmica e com minha própria formação docente.

Cada estudante imerso/a pelo orgulho de fazer parte de uma escola fixada no seu próprio chão e envolvido/a por memórias socioespaciais únicas, fez com que eu partilhasse do sentimento de pertencimento que facilitava o caminho para os processos de ensino/aprendizagem. Ao acolher as propostas, os/as estudantes manifestavam dedicação e prazer na realização dos trabalhos artístico-pedagógicos e contrariavam, dessa forma, as afirmações que negavam a capacidade destes/as estudantes periférico/as de acompanharem o trabalho pedagógico do colégio, segundo o depoimento do atual Reitor Prof. Oscar Halac em vídeo institucional em comemoração aos 10 anos do campus. 
Ao considerar esse contexto, por um momento, interrompemos o relato do acontecimento estético para pontuar aspectos fundamentais para a elaboração da análise que pretendemos fazer com este trabalho.

Em primeiro lugar, experiências visuais, no contexto escolar ou não, podem fortalecer noções de alteridade, cuja definição, como apresenta Ranciére (2012), amplia as compreensões sobre como compreendemos as imagens quando coloca em foco os efeitos que exercem no outro, no que sente e como sente.

Como Freire (1996) aponta, o professor que "desrespeita a curiosidade do educando, o seu gosto estético, a sua inquietude, a sua linguagem, mais precisamente, a sua sintaxe e a sua prosódia [...], transgride os princípios fundamentalmente éticos de nossa existência" (FREIRE, 1996, p.31).

Então o que se acredita a respeito de 'ensinar arte' cede espaço à concentração de esforços e atenção ao gestual do outro e também a toda rede de formas de se apreender algo com alguém; os sentidos que se atribuem às vivências e experimentações com uma imagem, por exemplo, não se limitam à palavra ou à tirania da letra, ou seja, mobilizam mais formas de compreensão e interpretação do que se vê numa dialética singular (RANCIÈRE, 2012). Desse modo, as imagens fotográficas dessa proposta, proporcionam vislumbrar um encontro de subjetividades por meio de afetos, afinal, o resultado do encontro corpo/palavra que evoca só adquire sentidos por se tratar de uma proposta participativa.

Em seguida, soma-se a essa reflexão, a ideia de que o Ensino de Artes Visuais hoje, sem perder de vista seus processos de ensino/aprendizagem específicos, caracteriza-se pela interação com outras áreas de conhecimento como a Filosofia, História, Língua Portuguesa, entre outras, de modo interdisciplinar, multidisciplinar e intercultural, relacionando os saberes e diálogos entre arte e educação e, acima de tudo com os discursos das imagens presentes na vida cotidiana. Para Ana Mae Barbosa, 
Em nossa vida diária, estamos rodeados por imagens impostas pela mídia, vendendo produtos, ideias, conceitos, comportamentos, slogans políticos etc. Como resultado de nossa incapacidade de ler essas imagens, nós aprendemos por meio delas inconscientemente. A educação deveria prestar atenção ao discurso visual. Ensinar a gramática visual e sua sintaxe através da arte e tornar as crianças conscientes da produção humana de alta qualidade é uma forma de prepará-las para compreender e avaliar todo tipo de imagem, conscientizando-as de que estão aprendendo com estas imagens. (BARBOSA, 1998, p. 17).

Essa concepção dialoga com as abordagens teórico-metodológicas deste trabalho quanto à Educação em Cultura Visual, cujo estudo converge diversas áreas de saber e consequentemente amplia o entendimento da participação da Arte na formação escolar. Sobre o conceito de Cultura Visual, Dias (2011) explica que seu surgimento como campo de estudo, ocorre no século XIX, e evidencia que as múltiplas representações visuais do cotidiano podem estimular produção, apreciação e crítica das artes, desenvolvendo cognição, imaginação e consciência social. O autor define Cultura Visual como

\footnotetext{
Estudos da cultura e do social e a várias disciplinas do conhecimento. Entre elas destacam-se a educação, sociologia, antropologia e geografia (...), com intenção de incluir num conceito comum todas as realidades visuais, as visualidades, sejam elas quais forem que afetam os sujeitos em seu cotidiano (Dias, 2011, p. 30).
}

Logo, a Cultura Visual possibilita que seus relevos estejam presentes e favoráveis à recontextualização das visualidades, ao diálogo crítico e à fruição para além dos preconceitos.

Ainda nesta perspectiva, Mirzoeff (2016) define as visualidades da Cultura Visual como um campo de batalha que usa ideias, informação, imagens e intuição. Também define como campo de estudo interdisciplinar, que na prática cria objetos que não pertencem a uma única área. Para ele, a cultura está em primeiro plano, sem perder de vista a questão política inerente. Em sua 
abordagem crítica, diversifica os canais de produção científica, quando propõe ir além das fronteiras tradicionais da academia e interagir com os cotidianos das pessoas.

\footnotetext{
"Esta é, então, a "cultura visual" do nosso tempo: uma circulação capitalizada de conjuntos de informação, traduzida em formato "visual" nos ecrãs dos nossos dispositivos, que possibilita e expande a circulação de mercadorias de todos os tipos. Além disso, estende a mercantilização da própria percepção como um bem monetizável. A investidora de risco americana Mary Meeker chama-lhe "tudo é visual, a toda a hora" [All visual, all the time]." (MIRZOEFF, 2016, p. 2)
}

Um outro aspecto que destacamos se refere à criação visual das juventudes em formação escolar. Em minha análise, o que produzem visualmente desafia as perspectivas hegemônicas e centralizadoras presentes na educação e na arte, pois atravessa-os com um frescor incontrolavelmente pleno de temas, alternativas e abordagens especialmente vigorosas. Suas formas particulares de expressão visual apontam para múltiplos lugares, por vezes de resistência autônoma, que avançam na contramão do que é estabelecido e aceito no mundo da arte e os coloca em posição de criadores e fruidores de sua própria arte como centralidade (DIAS, 2011). Mesmo que esse processo seja realizado pela perda do consenso e disputa por espaços no interior da escola (GRAMSCI, 1984; PY; PEDLOWSKI; 2018).

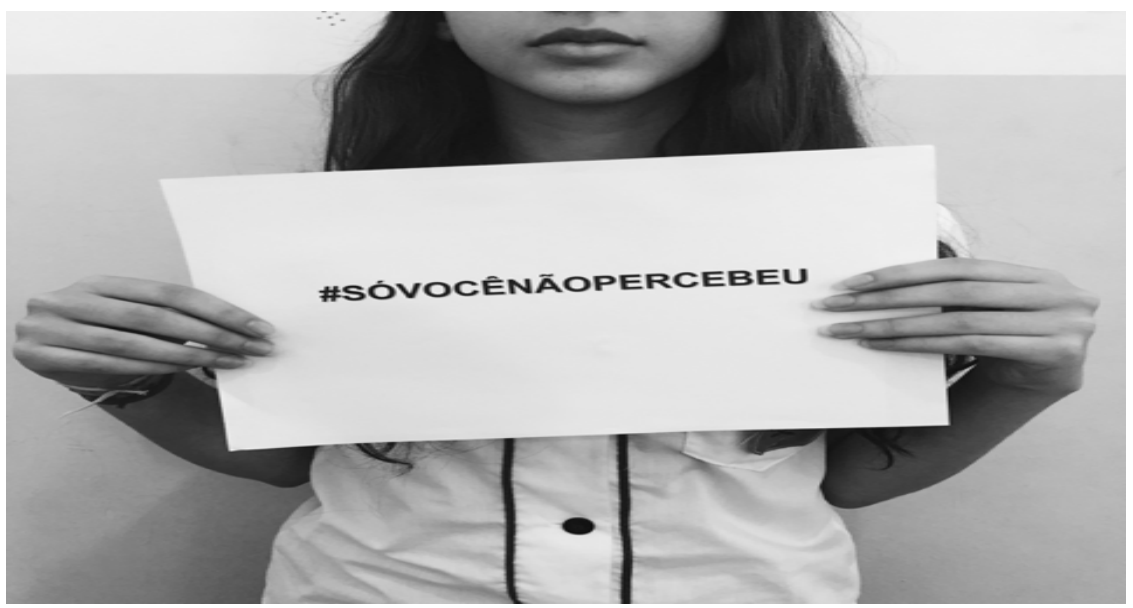

Imagem 2 - \#prontofalei, acervo do autor, 2014. 
A exemplo disso, antes de prosseguir com a proposta visual específica que inspira este trabalho, podemos mencionar as fotografias produzidas pela artista visual e professora Myllena Araújo - minha ex-aluna na Rede Privada em 2008, no Ensino Fundamental - que sugere a partir de seus autorretratos, realizados em 2008, características que evidenciam uma criação visual com personalidade e intencionalidade no processo criativo. Aspectos estes que vão desde o enquadramento que utiliza, uso dos contrastes e até mesmo um gestual que aponta para um "certo bom humor".

A artista relata ainda que tais imagens foram produzidas em série, quando saía da escola, sobretudo, após o término de nossas aulas de Artes Visuais. Ela afirma que as discussões realizadas em sala, mobilizavam nela a necessidade de expandir as experimentações poéticas e visuais que eram inicialmente pedagógicas.
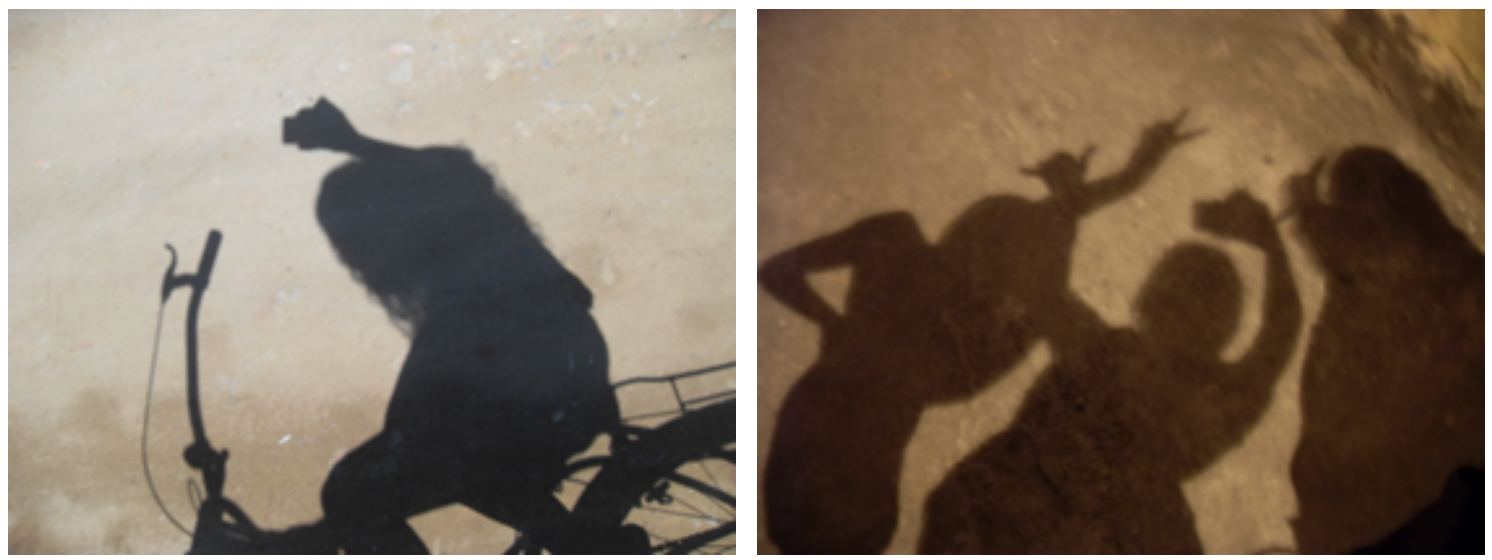

Imagem 3 - Autorretrato, acervo do autor, 2008.

Assim, o campo da Arte e seu ensino, por vezes, se reveste de um rigor metodológico e conteudista nos moldes tradicionais de procedimentos pedagógicos que, às vezes, as juventudes ultrapassam e transbordam, tal como percebemos nas imagens apresentadas no trabalho. 
Ao buscar referências que fundamentem as noções críticas no Ensino de Artes Visuais como meio para a formação cidadã na escola - entendese aqui, por formação cidadã, aquela que participa, define e escolhe seu processo político, cultural e social -, essas fotografias convergem de forma rizomática para múltiplas subjetividades, repertórios, culturas, visualidades e cotidianos, os quais dialogam com os processos de elaboração de discursos finalmente autorais (MARTINS E TOURINHO, 2011).

\section{\#prontofalei}

Se por um lado os estudos em Cultura Visual, no campo do Ensino de Artes Visuais, contribuem teórico-metodologicamente com as práticas visuais na educação, por outro, as questões relacionadas às subjetividades, engendram novos elementos aos processos educacionais.

Nesse ponto, retomamos a reflexão sobre a proposta pedagógica que instiga este trabalho, pois, para além de um relato sobre a experiência, há ideias e intenções claras por parte dos protagonistas da ação poética realizada, que nos ajudam a compreender melhor suas questões e, portanto, apontam para novas investigações artístico-metodológicas (BARBOSA, 1998).

O estudante L. (15 anos), escreve em sua publicação no Instagram:

\footnotetext{
“Trabalho de artes visuais da turma 2102 (2014).

Queremos provocar você e fazê-lo pensar sobre a força das afirmações e julgamentos que podem ser feitos em qualquer momento da vida. Neste trabalho o recurso da hashtag funciona como mecanismo atualizado de apresentação da ideia da nossa turma desdobrada em forma de performance, instalação e fotografia. \#prontofalei \#artecontemporânea".
}

Em termos poéticos, a ação artística dos/as estudantes, falava sobre conjugar ideias sobre os espaços da escola, deslizar entre suas dúvidas, interferir 
nos lugares comuns e impor seus corpos em virtude da participação de quem os assistia. Pois, como afirma Barbosa (2010), a arte, enquanto linguagem, aguça seus sentidos e transmite suas ideias de forma que tornem visíveis o que são, onde estão e como se sentem.

Sublinho que a fartura polissêmica- estabelecida pelos diálogos entre os/as estudantes, professor e demais espectadores do trabalho artístico -só ganha sentidos por meio da participação, das vozes e expressões resultadas da interação entre as pessoas envolvidas. Assim, espectadores, estudantes e obra fluem contínua e instigantemente, numa diversidade de leituras e interpretações, revelando a abrangência e potência simbólica do universo imagético na criação artística na/da escola e para fora dela.

Quando iniciamos a proposta visual - valendo-nos absolutamente dos significados da palavra proposta -, tínhamos em mente alguns aspectos próprios das obras de arte contemporâneas elencados nas aulas. Características como corpo como suporte, efemeridade, uso de materiais comuns e ordinários e até mesmo alguma rebeldia diante dos postulados das imagens tradicionais, insurgiam como um sopro que provocaria uma tempestade de ideias para as possíveis formas de execução do nosso trabalho.

Cabe mencionar que tanto as aulas e seus conteúdos, quanto a sugestão de trabalhos em Artes Visuais, são baseados metodologicamente no Projeto Político Pedagógico Institucional (PPPI), do Colégio Pedro II, para os anos de 2017 a 2020. O documento propõe que estudantes no 1o ano do Ensino Médio Regular - e Técnico em Informática e Meio Ambiente - devem "reconhecer as poéticas contemporâneas nas proposições artísticas e as formulações que as constituem", bem como "produzir/expressar plasticamente composições sobre os temas abordados no conteúdo", com ênfase em tema específicos, dentre eles a "Arte Contemporânea". O documento afirma: 


\begin{abstract}
“Devemos deixar, primeiro, que as obras dos artistas façam seu trabalho junto ao espectador, que elas falem por si próprias, provocando indagaç,ões, estranhezas, emoções, espantos ou mesmo incômodos. Os estudantes vão achar seu lugar nesse encontro, quanto mais se aproximarem, por si próprios, das obras. Os educadores não devem se assustar ou temer a desexplicação dos artistas, mas, ao contrário, devem penetrar na escuridão das incertezas junto com os estudantes, e contribuir para que dela emerja a luz de sua percepção." (CPII, 2018, p. 220)
\end{abstract}

O PPPI indica que o/a estudante deve reconhecer, identificar e refletir sobre as experiências poéticas contemporâneas. Mas estas ações são suficientes para a apreensão de conhecimentos estéticos, artísticos, culturais e políticos presentes na arte da contemporaneidade?

Como o documento oficial também orienta o planejamento docente, a proposta pedagógica exemplificada aqui utiliza-se de uma das diversas formas expressivas da arte contemporânea. No entanto, questionamos também até que ponto o documento contempla as demandas visuais de juventudes num contexto escolar tão específico.

Embora, a performance tenha sido a linguagem escolhida pelos/as próprios estudantes, também busco compreender quais influências o professor exerce sobre tais escolhas e, principalmente, como seus repertórios influenciaram essa escolha.

Vale ressaltar que a performance como expressão caracteriza-se como "forma de arte que combina elementos do teatro, da música e das artes visuais" (CHILVERS, 2007, p. 404). Teria sido esse o motivo?

Tal linguagem se articula com os aspectos efêmeros e passageiros da manifestação artística. Isso significa dizer que são manifestações que acontecem uma única vez, vidadas uma única fez e têm como registro apenas em forma de vídeo ou fotografia, como no caso das imagens apresentadas ao longo deste texto. 
Como percurso metodológico, a leitura de imagens foi uma das etapas que realizamos em aulas de Artes Visuais, com o objetivo de ampliar repertórios, estimular o pensamento crítico e contextualizar historicamente as imagens. No caso desta proposta, por exemplo, percebe-se o diálogo com as performances do Grupo Rex, formado por artistas radicados em São Paulo, dentre eles Nelson Leirner, Geraldo de Barros, Wesley Duke Lee, dentre outros. Em suas atividades artísticas entre os anos de 1966 e 1967, o grupo propunha ações artísticas nada convencionais, irônicas, críticas e contestadoras. Uma de suas atividades era a publicação do jornal REX TIME, cujo conteúdo criticava o sistema da arte, os aspectos dominantes dos jornais, dos museus, das bienais.

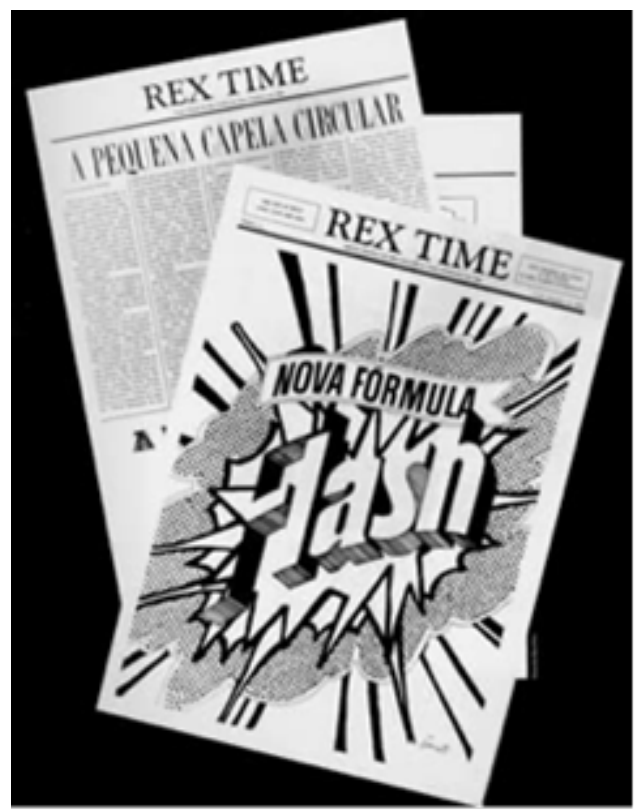

Imagem 5 - Jornal Rex Time, acervo do antor 2000

Uma das edições de 1966 anunciava: “Tem gente que, depois de pensar e sofrer bem, achou que do jeito que está a situação das artes plásticas no Brasil não pode continuar. E, sempre pensando bem e sofrendo mais ainda, eles resolveram dar um grito de 'basta!'. (...) Essas gentes são os Rex”. 
Observadas essas características, quando discutimos qual título nosso trabalho receberia, rapidamente subiu à tona o primeiro traço provocativo que estava por adquirir. Instigados pelos atributos da performance e por suas vivências nas redes sociais, a proposta recebeu o título \#prontofalei - ênfase garantida pela turma tanto na hashtag e quanto na tipografia em itálico. Com esse recurso de buscas em ambiente virtual, característico do símbolo \# (cerquilha), sabiamente a turma concluiu que, desse modo, ao ser veiculada na Internet, o trabalho seria facilmente encontrado, evidenciando então o sentido desse tipo de escrita junto à fotografia publicada.

Neste ponto do trabalho, faço menção às dúvidas que insurgem sobre em que medida a proposta serve ao currículo escolar ou o contrário, e sobretudo, quais transbordamentos esse tipo de proposta visual é capaz de estimular. Será que abordagens como essas de fato cedem espaço às subjetividades juvenis? Os currículos praticados consideram o devido espaço para suas criações? A escola, tal qual a conhecemos, acolhe estas visualidades? Talvez essas questões nunca possam ser respondidas ou solucionadas, e por isso, opto por debruçar-me sobre a riqueza das experiências vividas na ocasião.

A essa altura, o rigor do cumprimento do plano de aula ou mesmo o cumprimento literal do currículo, cederam espaço ao entusiasmo e criatividade de cada estudante mergulhado/a na proposta. Embora, tenha sido observada a timidez por parte de alguns, a proposta aconteceu a despeito da inicial resistência, diluída em meio ao fervor dos/as demais colegas da turma durante o acontecimento da performance. Não houve fim. Não se perguntava sobre qual nota foi atribuída. Doce e intensamente, vivemos aquela tarde. 


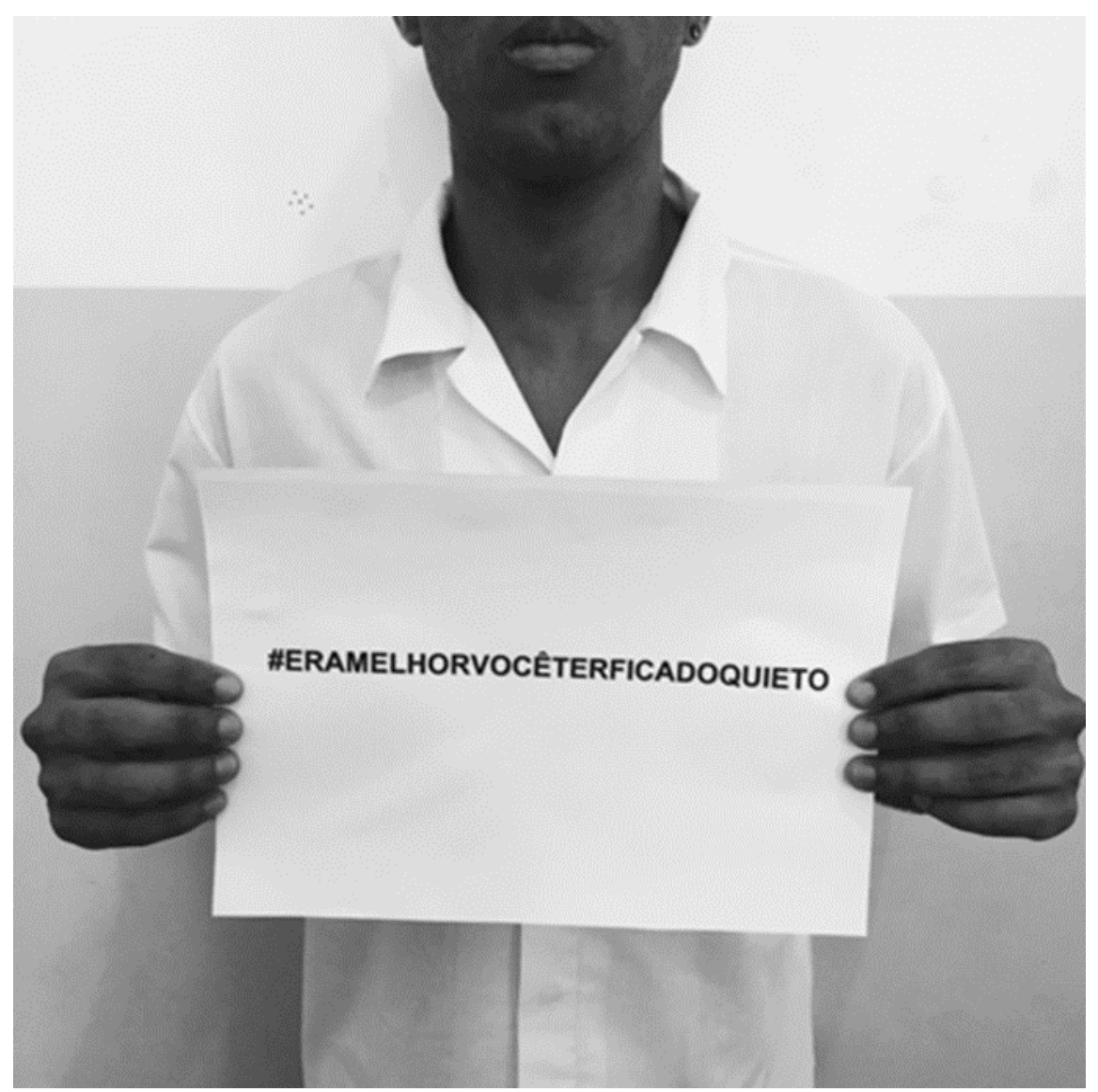

Imagem 4 - \#prontofalei, acervo do autor, 2014.

É difícil de inferir sobre como essas propostas alcançam as emoções e memórias de cada estudante, no entanto, diante do prazer estético experimentado por nós na ocasião do trabalho, inevitavelmente lembro-me de Gumbrecht (2010), quando fala sobre a herança cartesiana de percepção deixada para nossas culturas contemporâneas. Assim, a despeito disso, estávamos expostos/as à complexidade das nossas subjetividades, sim, nossas, em cada etapa da produção da performance, da nossa arte e da criação de poéticas visuais deliciosamente de nossa própria autoria. 


\section{Considerações Finais}

As visualidades produzidas em meio às aulas de Artes Visuais permitem vislumbrar não a criação de um novo mundo, mas a reelaboração do mundo presente e concreto dos/as estudantes. O repertório de saberes de cada estudante obviamente entra e faz a escola tanto ou maior que os conteúdos programáticos das disciplinas. Suas poéticas, vivências, experiências, aspectos subjetivos e ideias são constantemente carregadas de visualidade e dúvidas.

Cabe, nesses tempos, assumir uma pedagogia que se posicione criticamente ao invés da postura acrítica e meramente reprodutiva. No que diz respeito às visualidades, podemos percebê-las como objetos de conhecimento e na mesma medida, produtoras e mediadoras da Cultura Visual. Precisamos (re)discutir e (re)pensar sobre os discursos das imagens, e diante delas, não nos deixarmos furtar do que elas são hábeis em provocar.

Tal postura pedagógica no campo do Ensino de Artes Visuais decorre favoravelmente em novos olhares e novas visualidades em função da nitidez, do contraste, das cores, recortes visuais, bem como as histórias de vida, os afetos, os desejos, as autorrepresentações, as representações coletivas e demais aspectos vitais à formação humana que são carregados de sentidos e em constante diálogo com tudo que envolve estudantes e sua formação dentro e fora da escola.

\section{Referências}

AVISO: É a Guerra (1966 : São Paulo, SP). In: ENCICLOPÉDIA Itaú Cultural de Arte e Cultura Brasileiras. São Paulo: Itaú Cultural, 2020. Disponível em: $<$ http://enciclopedia.itaucultural.org.br/evento84657/aviso-e-a-guerra-1966-saopaulo-sp>. Acesso em: 09 de Mai. 2020

BARBOSA, Ana Mae. Tópicos utópicos. Belo Horizonte: Com Arte, 1998. 
- (orgs.). Arte/Educação contemporânea: consonâncias internacionais. 3. ed. São Paulo: Cortez, 2010.

BRASIL. Instituto Nacional de Estudos e Pesquisas Educacionais Anísio Teixeira (INEP). Censo Escolar de 2014. Disponível em: <http://portal.inep.gov.br/censoescolar>. Acessado em 17 mai. 2020.

CHILVERS, Ian (org.). Dicionário Oxford de Arte. Tradução Marcelo Brandão Cipolla. 2.ed. São Paulo: Martins Fontes, 2001.

COLÉGIO PEDRO II (CPII). Projeto Político Pedagógico Institucional: Colégio Pedro II 2017/2020. Rio de Janeiro: CPII, 2018. Disponível em: <http://www.cp2.g12.br/images/comunicacao/2018/JUL/PPPI\%20NOVO.pdf $>$. Acessado em: 17 mai. 2020.

DELEUZE, Gilles. Espinosa e a Filosofia Prática. Traducão de Daniel Lins e Fabien Pascal Lins. São Paulo: Escuta, 2002.

DIAS, Belidson. O I/mundo da Educação em Cultura Visual. Distrito Federal: Editora da Pós-graduação em Arte da Universidade de Brasília, 2011.

FREIRE, P. Pedagogia da autonomia: saberes necessários à prática educativa. São Paulo: Paz e Terra, 1996.

GRAMSCI, Antonio. Os intelectuais e a organização da cultura. Rio de Janeiro: Civilização brasileira, 1984.

GRUPO Rex. In: ENCICLOPÉDIA Itaú Cultural de Arte e Cultura Brasileiras. São Paulo: Itaú Cultural, 2020. Disponível em: $<$ http://enciclopedia.itaucultural.org.br/grupo434025/grupo-rex>. Acesso em: 09 de Mai. 2020.

MARTINS, Raimundo; TOURINHO, Irene (organizadores). Educação da Cultura Visual: conceitos e contextos. Santa Maria: Ed. UFSM, 2011.

GUMBRECHT, Hans Ulrich. Produção de Presença. O que o sentido não consegue transmitir. Rio de Janeiro: Contraponto: Editora PUC-Rio, 2010.

MIRZOEFF, Nicholas. O direito a olhar. ETD - Educação Temática Digital, Campinas, SP, v. 18, n. 4, p. 745- 768, nov. 2016. ISSN 1676-2592. Disponibilidade 
em: <http://periodicos.sbu.unicamp.br/ojs/index.php/etd/articleview/8646472>. Acessado em: 16 set. 2019. doi:http://dx.doi.org/10.20396/etd.v18i4.8646472.

PONTUAL, Roberto. Arte brasileira contemporânea: Coleção Gilberto Chateaubriand. Apresentação Pereira Carneiro; tradução Florence Eleanor Irvin, John Knox. Rio de Janeiro: Edições Jornal do Brasil, 1976.

PY, F.; PEDLOWSKI, M. A. Atuação de religiosos luteranos nos movimentos sociais rurais no Brasil (1975-1985). In: Tempo Vol. 24 n. 2 Maio/Ao. 2018. Disponível em: <https://www.scielo.br/pdf/tem/v24n2/1980-542X-tem-24-02233.pdf>. Acessado em 15 mai. 2020.

RANCIÈRE, Jacques. O destino das imagens. Rio de Janeiro: Contraponto, 2012.

VIANA, Claudis Gomes de Aragão. A Fábrica de cartuchos do Realengo (1898 1977). In: Revista Digital Simonsen. Rio de Janeiro, n.4, Jun. 2016. Disponível em: <www.simonsen.br/revistasimonsen>. Acessado em: 15 mai. 2020. 